\title{
The missing link in lysosomal enzyme targeting
}

\author{
William S. Sly \\ Department of Biochemistry, St. Louis University School of Medicine, 1402 South Grand Boulevard, St. Louis, \\ Missouri 63104, USA. Phone: (314) 577-8131; Fax: (314) 776-1183; E-mail: slyws@slu.edu.
}

In this issue of the JCI, Raas-Rothschild et al. (1) elucidate the mechanism of a rare inherited disorder of lysosomal enzyme targeting, mucolipidosis IIIC. In so doing, they add an important piece to the puzzle of how cells target lysosomal enzymes to lysosomes (for reviews, see refs. 2 and 3), and put some finishing touches on an important chapter in cell biology.

The story began in 1967 when Leroy and DeMars (4) described a new disorder that clinically resembled Hurler syndrome, but lacked mucopolysacchariduria. Another distinguishing feature was the presence of large, phase-dense inclusions in patient fibroblasts. Because these cells were called inclusion cells (Icells), the disorder came to be called I-cell disease. Similar inclusions were seen in pseudo-Hurler polydystrophy, which was clinically milder than I-cell disease and presented later (5).

Subsequently, Spranger and Weidemann (6) coined the term mucolipidosis to denote diseases that combined features of the mucopolysaccharidoses and the sphingolipidoses. In this classification, I-cell disease was called mucolipidosis II and pseudo-Hurler polydystrophy was called mucolipidosis III. Although this classification is not ideal, because the 2 disorders are fundamentally different than the other lysosomal storage diseases, the terms and their abbreviations MLII and MLIII are generally accepted in the literature. Somatic cell geneticists identified 3 complementation groups of MLIII patients that were labeled MLIII A, B, and C (B representing only 1 patient), suggesting genetic heterogeneity in MLIII.

What has made these related autosomal recessive inherited diseases so important is not their frequency - both are rare - but the clues they provided investigators elucidating the pathway by which acid hydrolases are targeted to lysosomes. By the early 1970s, other biochemical abnormalities were observed in I-cell disease. Cultured fibroblasts were found to be deficient for multiple acid hydrolases, many of which were present in abnormally high levels in cul- ture medium $(7,8)$. In addition, the serum and body fluids of such patients show elevated levels of these lysosomal enzymes. Similar biochemical abnormalities were identified in MLIII (9). Hickman and Neufeld (10) made the key observations that I-cell fibroblasts were capable of endocytosis of acid hydrolases secreted by normal fibroblasts, but that the enzymes secreted in excess by I-cell fibroblasts were not subject to endocytosis by normal fibroblasts. These observations suggested that lysosomal enzymes contain a recognition marker for uptake and transport to lysosomes and that the enzymes secreted by I-cell fibroblasts lack this marker (11). This hypothesis was subsequently confirmed, and the recognition marker was identified as mannose 6-phosphate in Sly's laboratory $(12,13)$.

The biosynthetic pathway by which the mannose 6-phosphate is added to newly synthesized acid hydrolases was elucidated in the Kornfeld (14) and von Figura (15) laboratories. The mechanisms for processing and targeting acid hydrolases to lysosomes involve some of the same machinery used for synthesis of other glycoproteins. Lysosomal enzymes are synthesized on membrane-bound ribosomes and translocated to the lumen of the endoplasmic reticulum, where $N$-linked oligosaccharide chains are added (14). After transfer to the Golgi apparatus, mannose 6-phosphate residues are added to acid hydrolases in a process that requires the sequential action of 2 enzymes. The first catalyzes the addition of an $\alpha$ - $N$-acetylglucosamine 1-phosphate residue to the 6 position of mannoses on high-mannose oligosaccharide chains. The second enzyme removes $N$ acetylglucosamine to expose the mannose 6-phosphate. The "uncovering enzyme" was recently characterized and shown to be a tetramer composed of 2 disulfidelinked homodimers of 68-kDa subunits. To date, no disease has been attributed to a deficiency of this enzyme (16).

Cells from patients with I-cell disease and MLIII were shown to be deficient in the first enzyme in this pathway (UDP-
$N$-acetylglucosamine:lysosomal enzyme $\mathrm{N}$-acetylglucosamine 1-phosphotransferase). As early as 1981, it was clear that there was a variant form of MLIII that had normal catalytic activity with $\alpha$ methylmannoside but failed to recognize acid hydrolases normally (17). Varki et al. inferred that the catalytic and recognition domains of the enzyme resided on different subunits. Work from the Kornfeld laboratory, using bovine cathepsin D and cathepsin Dpepsin chimeric enzymes, identified 3dimensional patches that serve as recognition domains for the phosphotransferase (18).

Once the absence of the phosphotransferase was shown to be the molecular basis of I-cell disease and MLIII $(14,15)$, and the enzyme proposed to be

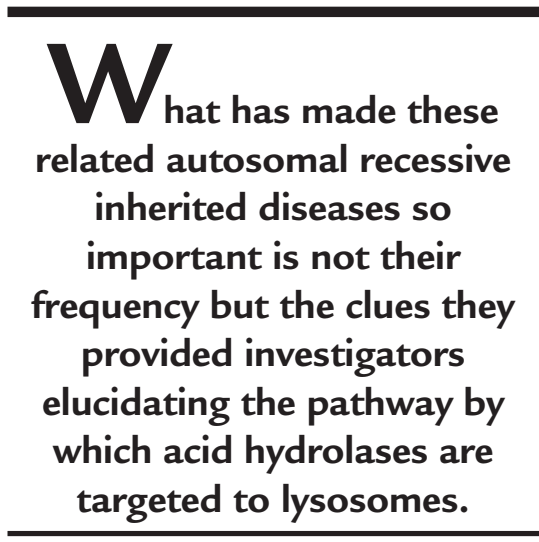

a multisubunit enzyme, acquiring enough purified phosphotransferase to test this hypothesis became the elusive Holy Grail of the lysosomal enzyme sorting field. Nearly 15 years later, the Canfield laboratory succeeded in purification of the enzyme as a $54-\mathrm{kDa} \alpha_{2} \beta_{2} \gamma_{2}$ hexameric complex (19). Unpublished data cited in the Raas-Rothschild article (1) show that many patients with Icell disease lack the transcript whose product is cleaved to form the $\alpha$ and $\beta$ subunits of the phosphotransferase. The article also reports the isolation of the cDNA for the $\gamma$ subunit, maps its gene to chromosome $16 \mathrm{p}$, and provides evidence that affected members of 3 
families with variant MLIII have the same single base insertion resulting in a frameshift and early termination of this subunit. This beautiful set of experiments neatly closes the circle on the enzymology of lysosomal enzyme recognition and provides evidence that the original "Iranian patients," whose cell provided Varki et al. (17) the key to the lysosomal enzyme recognition defect, lacked the $\gamma$ subunit.

Wonderful as this story is, it does not answer all the mysteries of I-cell disease and MLIII. A yet-unexplained feature of these disorders is that not all cells in Icell disease are deficient in lysosomal enzymes, even though all cells examined to date are deficient for phosphotransferase activity (2). Several cell types (e.g., hepatocytes, Kupffer cells, and leukocytes) and several organs (e.g., liver, kidney, and brain) appear to have nearly normal levels of most lysosomal enzymes in I-cell disease. Thus, mannose 6-phosphate is not the only ticket to lysosomes. There must be alternate pathways. In fact, 2 acid hydrolases, acid phosphatase and glucocerebrosidase, do not use the mannose 6-phosphate targeting pathway in any cell type. Acid phosphatase is made as a transmembrane protein, and the signal for its lysosomal targeting is contained in the cytoplasmic tail. The targeting mechanism for glucocerebrosidase remains to be clarified, as do the other mannose 6-phosphate-independent routes to lysosomes that provide lysosomal proteins to certain cells and organs in patients with I-cell disease. Nonetheless, the work presented by Raas-Rothschild et al. elucidates the molecular genetics of the mannose 6-phosphate-dependent pathway of lysosomal enzyme targeting and definitively establishes the molecular basis for the genetic heterogeneity in MLII and MLIII.

1. Raas-Rothschild, A. et al. 2000. Molecular basis of variant pseudo-Hurler polydystrophy (mucolipidosis IIIC). J. Clin. Invest. 105:673-681 (2000).

2. Kornfeld, S., and Sly, W.S. 1995. I-cell disease and pseudo-Hurler polydystrophy: disorders of lysosomal enzyme phosphorylation and localization. In The metabolic and molecular bases of inherited disease. C.R. Scriver, A.L. Beaudet, W.S. Sly, and D. Valle, editors. McGraw-Hill. New York, NY. 2495-2508.

3. Dahms, N.M., Lobel, P., and Kornfeld, S. 1989 Mannose 6-phosphate receptors and lysosomal enzyme targeting. J. Biol. Chem. 264:12115-12118.

4. Leroy, J.G., and DeMars, R.I. 1967. Mutant enzymatic and cytological phenotypes in cultured human fibroblasts. Science. 157:804-806.

5. Kelly, T.E., et al. 1975. Mucolipidosis III (pseudoHurler polydystrophy): clinical and laboratory studies in a series of 12 patients. Johns Hopkins Med.J. 137:156-175.

6. Spranger, J.W., and Weidemann, H.R. 1970. The genetic mucolipidoses. Humangenetik. 9:113-139.

7. Tondeur, M., et al. 1971. Clinical, biochemical, and ultrastructural studies in a case of chondrodystrophy presenting the I-cell phenotype in culture. J. Pediatr. 79:366-378.

8. Lightbody, J., Weissmann, U., Hadorn, B., and Herschkowitz, N. 1971. I-cell disease: multiple lysosomal-enzyme defect. Lancet. 1:451.

9. Glaser, J.H., McAlister, W.H., and Sly, W.S. 1974. Genetic heterogeneity in multiple lysosomal hydrolase deficiency. J. Pediatr. 85:192-198.

10. Hickman, S., and Neufeld, E.F. 1972. A hypothesis for I-cell disease: defective hydrolases that do not enter lysosomes. Biochem. Biophys. Res. Commun. 49:992-999.

11. Hickman, S., Shapiro, L.J., and Neufeld, E.F. 1974. A recognition marker required for uptake of a lysosomal enzyme by cultured fibroblasts. Biochem. Biophys. Res. Commun. 57:55-61.

12. Kaplan, A., Achord, D.T., and Sly, W.S. 1977. Phosphohexosyl components of a lysosomal enzyme are recognized by pinocytosis receptors on human fibroblasts. Proc. Natl. Acad. Sci. USA. 74:2026-2030.

13. Natowicz, M.R., Chi, M.M.-Y., Lowry, O.H., and Sly, W.S. 1979. Enzymatic identification of mannose 6-phosphate on the recognition marker for receptor-mediated pinocytosis of $\beta$-glucuronidase by human fibroblasts. Proc. Natl. Acad. Sci. USA. 76:4322-4326.

14. Kornfeld, S. 1987. Trafficking of lysosomal enzymes. FASEB J. 1:462-468.

15. von Figura, K., and Hasilik, A. 1986. Lysosomal enzymes and their receptors. Annu. Rev. Biochem. 55:167-193.

16. Kornfeld, R., Bao, M., Brewer, K., Noll, C., and Canfield, W.M. 1998. Purification and multimeric structure of bovine $\mathrm{N}$-acetylglucosamine-1phosphodiester- $N$-acetylglucosaminidase. J. Biol. Chem. 273:23203-23210.

17. Varki, A.P., Reitman, M.L., and Kornfeld, S. 1981 Identification of a variant of mucolipidosis III (pseudo-Hurler polydystrophy): a catalytically active $N$-acetylglucosaminylphosphotransferase that fails to phosphorylate lysosomal enzymes. Proc. Natl. Acad. Sci. USA. 78:7773-7777.

18. Baranski, T.J., Cantor, A.B., and Kornfeld, S. 1992 Lysosomal enzyme phosphorylation. I. Protein recognition determinants in both lobes of procathepsin D mediate its interaction with UDP-GlcNac:lysosomal enzyme $N$-acetylglucosamine-1phosphotransferase. J. Biol. Chem. 267:23342-23348.

19. Bao, M., Booth, J.L., Elmendorf, B.J., and Canfield W.M. 1996. Bovine UDP- $N$-acetylglucosamine:lysosomal enzyme $\mathrm{N}$-acetylglucosamine-1-phosphotransferase. I. Purification and subunit structure. J. Biol. Chem. 271:31437-31445. 